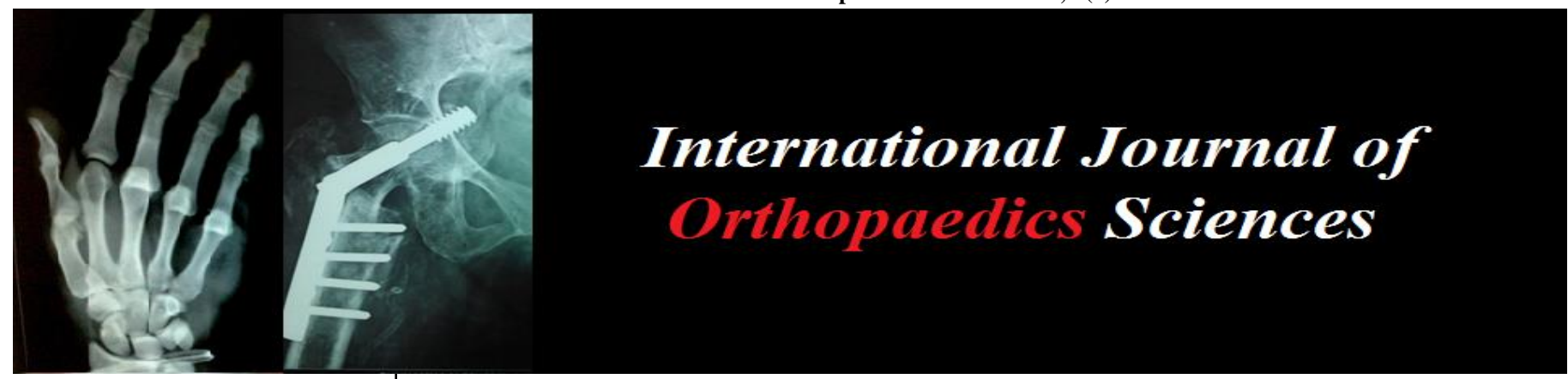

ISSN: $2395-1958$

IJOS 2019; 5(2): 954-960

(C) 2019 IJOS

www.orthopaper.com

Received: 24-02-2019

Accepted: 28-03-2019

Dr. Pradeep Kamboj

Professor, Department of Orthopaedics, PGIMS, Rohtak,

Haryana, India

Dr. Pankaj Kumar Sharma Assistant Professor, Department of Orthopaedics, PGIMS,

Rohtak, Haryana, India

Dr. Bhaumik Jesadia

Resident (Post-graduate),

Department of Orthopaedics,

PGIMS, Rohtak, Haryana, India

Dr. Sahil Arora

Assistant Professor, Department of Orthopaedics, PGIMS,

Rohtak, Haryana, India

Dr. Ram Chandra Siwach

Senior Professor, Department of Orthopaedics, PGIMS, Rohtak,

Haryana, India
Correspondence

Dr. Pankaj Kumar Sharma

Assistant Professor, Department

of Orthopaedics, PGIMS,

Rohtak, Haryana, India

\section{A comparative prospective study of osteosynthesis in intertrochanteric fractures, using dynamic hip screw (DHS) and proximal femoral nailing (PFN)}

\author{
Dr. Pradeep Kamboj, Dr. Pankaj Kumar Sharma, Dr. Bhaumik Jesadia, \\ Dr. Sahil Arora and Dr. Ram Chandra Siwach
}

DOI: https://doi.org/10.22271/ortho.2019.v5.i2n.1463

\begin{abstract}
Background: Intertrochanteric fractures (IT) are fragility fractures of hip and mostly associated with senile osteoporosis with trivial trauma or low velocity injuries. Traditionally extramedullary osteosynthesis in form of dynamic hip screw (DHS) was treatment of choice for these fractures in past but recent trends are more in favors of intramedullary osteosynthesis as proximal femoral intramedullary nailing (PFN). Here we studied and compared the radiological and functional evaluation of treatment parameters of these fractures managed with both modalities of treatment.

Methods: This prospective randomized study was conducted on 42 patients (21 patients in each group, group A, DHS; group B, PFN) with intertrochanteric fracture managed in two years of duration (July 2014 to June 2016). All the per-operative findings and complications were compared, while radiological assessment with radiographs and functional evaluation with Harris hip score was done at 1, 3 and 6 months post-operative follow-ups.

Results: Mean age of patients were 56.14 years (range 25-84), and 56.19 years (range 28-80), in group A and B respectively. We observed that PFN had less mean blood loss $(144 \mathrm{ml})$, less mean limb length shortening $(0.5 \mathrm{~cm})$ and gained better mean functional results at 6 months (Harris hip score, 86.9) due to early mobilization while patients managed with DHS had more blood loss $(155 \mathrm{ml})$, more shortening $(1.07 \mathrm{~cm})$ and less functional outcomes at 6 months follow-up (scores, 77.2). Intra-operative radiation exposure was more in PFN group, while there was no significant difference in radiological union, neckshaft angle and implant sliding in both groups.

Conclusion: PFN was better than DHS in management of intertrochanteric fractures in terms of peroperative parameters (decreased blood loss, less complications), and as well as in functional outcomes (early weight bearing and mobilization, better Harris hip scores), while other parameters are not significantly different.
\end{abstract}

Keywords: intertrochanteric fractures, dynamic hip screw (DHS), proximal femoral nail (PFN)

\section{Introduction}

The incidence of pertrochanteric fractures is toward increasing trend due to longevity of life and rising elderly population. According to a study for world-wide incidence the total number of hip fractures may reach 2.6 million by 2025 and 4.5 million by 2050 worldwide, making it one of the most frequently operated fractures and a serious health resource issue due to the high cost of post-injury care and morbidity ${ }^{[1-3]}$. In developing countries as India where prevalence of osteoporosis is high in the elderly population, these fractures pose an economic burden, as they occur in patients with co-morbidities which influence the quality of life and also increase the cost of treatment for the health systems. This situation demands Prompt surgical fixation and fast-track rehabilitation programs to facilitate rapid recovery, mobilization, and decrease the intra-operative and post-operative complications ${ }^{[4-6]}$. If suitable precautions are not taken, the fracture may unite in a position of coxavara with shortening of the limb and limitation of hip movements. Thus treatment should be so planned as to encourage union without deformity and at the same time allow early mobilization prompt return to pre-fracture activity levels ${ }^{[7-9]}$. Non-operative treatment should only be considered in patients who are non-ambulatory, having chronic dementia, and suffering from terminal 
Diseases with less than 6 weeks of life expectancy or unresolved medical co-morbidities that preclude surgical treatment. Stable fixation in pertrochanteric fractures that maintains reduction and allows early weight bearing is essential to achieve the best functional outcome. The sliding hip screw has been the implant of choice for stabilizing both stable and unstable intertrochanteric fractures, however, excessive fracture collapse, medialization of the femur, and limb shortening are known complications with the use of sliding hip screw leading to the development of intramedullary implants ${ }^{[10-12]}$. Cephalomedullary nails are biomechanically superior and have theoretical advantages like percutaneous insertion technique leading to minimal issue trauma, reduced blood loss, short operating time thus less chances of infection.

Present study was taken up to analyze the surgical management of trochanteric fractures of femur with Cephalomedullary Nail (CMN) and extramedullary hip screws and plates, its clinical outcomes, advantages and disadvantages, complications associated with the procedures, the effectiveness of surgical treatment and failure rates of both the implants.

\section{Material and Methods}

The present prospective randomized study was conducted on 42 patients presenting with intertrochanteric fracture in two years duration (July 2014 to June 2016) at our institute. All patients underwent a process of randomization by enveloped chit method and divided into 2 groups; group a (extramedullary implant, DHS), group B (intramedullary implant, Cephalomedullary nail). Ethical approval was granted from institutional ethical board while informed and written consent was taken from all the participants before enrolling into the study.

However patients with previous surgery of the proximal femur, fracture more than 15 day duration, undisplaced stable fractures, pathological fractures due to malignancy or chemoradiotherapy and severe systemic co-morbidities/illness rather than osteoporosis were excluded from the study. Patient's demographic profile, pre trauma activity level and range of motion in the normal hip were recorded in the performa. All the fractures were classified as per AO/OTA classification system using standard radiographs antero-posterior views of the hip and proximal femur. All the subjects were temporarily immobilized over a Bohler Braun splint with skeletal traction to maintain the length of the lower limb which facilitates subsequent definitive surgical procedure later on.

All the patients were operated under spinal/regional anaesthesia after optimizing underlying systemic comorbidities. In group A, all the patients were operated in supine position over the operation table under image intensifier guidance. First of all fracture reduced by closed manipulation and secured with instruments, while longitudinal traction was maintained upto final implantation. Those fractures, which were not reduced by closed maneuvers, open reduction were attempt. In group B patients that were managed by Cephalomedullary nail, Patients were laid in supine position and hip placed in a slight adduction position to facilitate insertion of the nail while longitudinal traction was applied to the fractured limb manually. In few patients lateral position was used as in fatty patients nail entry point and reaming became easier in lateral position but poor intra-operative lateral view was a drawback. Intravenous broad spectrum antibiotics (after sensitivity test) were started just before surgery and continued for 3 days postoperatively. Appropriate physiotherapy as tolerated by patients was started from very first day and partial weight bearing was started with the help of a walker as soon as possible. Stitch removal was done at 2 weeks then followed monthly for a minimum period of six months with variable parameters. Full weight bearing was allowed after bony union achieved, assessed by radiographs of bilateral hips with pelvis and operated hip with thigh (AP and lateral views) taken on 1 month, 3 months and 6 months intervals. Ambulatory functions at pre-injury and post-surgery periods were measured using the Parker Mobility Score (PMS) and score of $<5$ in the presence of an intertrochanteric fracture predicted inability to regain independent mobility ${ }^{[13,14]}$. Ambulatory function was further subdivided into ambulatory independence and environmental mobility while results were assessed by Harris Hip Score at final follow-up of 6 months ${ }^{[15]}$.

\section{Statistical analysis}

Patients in all the groups were compared and analyzed by software SPSS version 20.0, using descriptive statistical methods including the Pearson Chi squared test and student- $t$ test. Post-hoc test was applied to compare multiple variables. A $p$ value of $<0.05$ was considered statistically significant.

\section{Results}

Both the groups were comparable in the characteristic of pre injury and injury parameters as tabulated in table 1 . There were 21 patients each in both groups with 15 males and 6 females in each group, while mean age of patients were 56.14 years (range 25-84), and 56.19 years (range 28-80), in group $\mathrm{A}$ and $\mathrm{B}$ respectively. In group A, $47.6 \%$ of the patients used to walk with support (rest $52.4 \%$ without support) while in group B, $33.3 \%$ of patients walk with support (rest $66.7 \%$ without support) previous to injury and fracture. According to AO/OTA classification, majority of the fractures in both the groups were of $31-\mathrm{A} 2$ type, including $71.4 \%$ in group A and $66.7 \%$ in group B patients. Associated injuries were included; 2 patients with fracture of distal end of radius $(4.8 \%)$, one with fracture proximal humerus $(2.4 \%)$, fracture ulna $(2.4 \%)$ caused by assault and traumatic below knee amputation $(2.4 \%)$ of contra lateral limb resulted from mangled extremity in RTA.

Parameters observed during intra-operative and post-operative period in form of different variables were compiled in table 2 . All the patients were operated in spinal anaesthesia with supine position in group A while in group B, seven out of the 21 patients were operated in lateral position. Closed reduction of fractures was achieved in 16 out of 21 patients in group A while in group $B, 28.6 \%(n=6)$ of the patients under went open reduction, as closed reduction could not be achieved. Mean duration of surgery was 102.38 minutes (range, 75-135 min) in group A while in group B it was 111.90 minutes (range, 80-145 $\mathrm{min}$ ).

Table 1: Comparison of pre-injury and injury parameters in group A and group B.

\begin{tabular}{|c|c|c|c|}
\hline Parameters & Group A (DHS) & Group B (PFN) & P value \\
\hline No of patients & 21 & 21 & $>0.05$ \\
\hline age & $56.14 \pm 18.469$ & $56.19 \pm 17.437$ & $>0.05$ \\
\hline Sex distribution & $\mathrm{M}=15, \mathrm{~F}=6$ & $\mathrm{M}=15, \mathrm{~F}=6$ & $>0.05$ \\
\hline
\end{tabular}




\begin{tabular}{|c|c|c|c|}
\hline BMI & $24.738 \pm 1.4055$ & $24.962 \pm 1.9701$ & $>0.05$ \\
\hline Laterality & Lt-47.6\%, Rt-52.4\% & Lt $-42.9 \%$, Rt- $57.1 \%$ & $>0.05$ \\
\hline \multirow{2}{*}{ Pre Injury Mobility } & Walk with support- $47.6 \%$ & Walk with support-33.3\% & \multirow{2}{*}{$>0.05$} \\
\hline & Walk without support-52.4\% & Walk without support-66.7\% & \\
\hline \multirow{3}{*}{ Mode Of Trauma } & Assault- $4.8 \%$ & Assault-. $0 \%$ & \multirow{3}{*}{$>0.05$} \\
\hline & Domestic fall- $76.2 \%$ & Domestic fall $-47.6 \%$ & \\
\hline & RTA- $19.0 \%$ & RTA-52.4\% & \\
\hline Fracture type according to AO/OTA Classification & \begin{tabular}{|l|l|l|}
$31-\mathrm{A} 1$ (3) & 31-A2 (15) & 31-A3 (3) \\
\end{tabular} & \begin{tabular}{|l|l|l|}
$31-\mathrm{A} 1(1)$ & $31-\mathrm{A} 2(14)$ & $31-\mathrm{A} 3(21)$ \\
\end{tabular} & $>0.05$ \\
\hline
\end{tabular}

Table 2: Comparison of intra-operative and post-operative parameters in group A and group B.

\begin{tabular}{|c|c|c|c|}
\hline Parameters & Group A (DHS) & Group B (CMN, PFN) & P value \\
\hline Fracture Reduction & Closed $\mathrm{n}=16$ Open $\mathrm{n}=05$ & Closed $\mathrm{n}=15$ Open $\mathrm{n}=6$ & $>0.05$ \\
\hline Duration of Surgery & $102.38 \pm 14.96$ & $111.90 \pm 17.564$ & $>0.05$ \\
\hline Intra-operative Blood loss & $(155.71 \pm 37.626) \mathrm{ml}$ & $(144.29 \pm 48.639) \mathrm{ml}$ & $>0.05$ \\
\hline $\begin{array}{c}\text { Intra-operative Radiation } \\
\text { Exposure }\end{array}$ & $0.5186 \pm 0.17667(\mathrm{~min})$ & $0.6833 \pm 0.33461(\mathrm{~min})$ & $>0.05$ \\
\hline Hospital Stay (Days) & $9.43 \pm 2.063$ & $9.52 \pm 2.522$ & $>0.05$ \\
\hline Weight bearing (days) & $\begin{array}{c}\text { (Partial) } 44.21 \pm 14.555 \\
\text { (Full) } 87.89 \pm 16.357\end{array}$ & $\begin{array}{c}\text { (Partial) } 13.90 \pm 9.29 \\
\text { (Full) } 49.20 \pm 10.180\end{array}$ & $<0.05$ \\
\hline Radiological union (wks) & $15.84 \pm 1.463$ & $14.30 \pm 1.380$ & $>0.05$ \\
\hline Limb length discrepancy & $1.07 \pm 0.189(\mathrm{~cm})$ & $0.50 \pm 0.000(\mathrm{~cm})$ & $<0.05$ \\
\hline Implant sliding (cm) & $0.63 \pm 0.263$ & $0.72 \pm 0.403$ & $>0.05$ \\
\hline Neck-shaft angle (degrees) & immediate post op (131.95) final follow up \\
$(126.37)$ & $\begin{array}{c}\text { immediate post op (130.14) final follow up } \\
(128.35)\end{array}$ & $>0.05$ \\
\hline
\end{tabular}

Average intra-operative blood loss was $155.71 \mathrm{ml}$ in group A, while in group B, it was $144.29 \mathrm{ml}$, however mean intraoperative radiation exposure was 0.5186 minutes in group $\mathrm{A}$ and 0.6833 minutes in group $\mathrm{B}$ subjects. Mean duration of hospital stay was 9.43 days and 9.52 days in group A and B respectively. Partial and full weight bearing was allowed after an average period of 44.21 and 13.90 days in group a while for group B, these values were 87.89 and 49.20 days respectively. Time to union as assessed radiologically was 15.84 weeks in group A, while it was little earlier i.e. 14.30 weeks in group B patients. There was mean shortening of limb by $1.07 \mathrm{~cm}$ in group A and $0.50 \mathrm{~cm}$ in group B while mean sliding of the implant was $0.63 \mathrm{~cm}$ and $0.72 \mathrm{~cm}$ in group A and B patients respectively. Neck-shaft angle in immediate post op and at final follow up in group A patients was 131.95 and 126.37 degrees while in group B it was 130.14 and 128.35 degrees respectively. Mean difference between immediate post-op and final follow up neck shaft angle was 5.58 degrees in group $\mathrm{A}$, while in group $\mathrm{B}$, it was
1.85 degrees. Mean Parker Mobility Score at final follow-up in group A was 5.95 and in group B was 6.80. Environmental Mobility Score at final follow up was 2.26 in group A and 2.40 in group B while Ambulatory Independence score was 3.947 in group A and 4.157 in group B. Mean Harris hip score at 6 month in group A and group B are 77.26 and 86.95 . Difference of both the groups is statistically significant $(\mathrm{p}=0.033)$. Functional outcomes (Harris Hip Score) at final follow-up and pre-operative time in both the groups are compared in table 3. Functional results were observed excellent ( $\mathrm{n}=7$ and 10), good ( $\mathrm{n}=4$ and 7$)$, fair ( $\mathrm{n}=3$ and 2$)$ and poor ( $\mathrm{n}=7$ and 2$)$ in group $A$ and $B$ respectively, as per Harris Hip Score measurement. One patient had broken implant barrel and other had screw cut out for which re-surgery was done in group A, while there was no implant failure in group B patients. However, there was no mortality reported in the immediate post op period or during hospital stay in any of the groups.

Table 3: Functional outcome assessment (Harris Hip Score), pre-operatively and at final follow-up (6 month).

\begin{tabular}{|c|l|c|c|c|c|}
\hline \multicolumn{2}{|c|}{ Functional Outcome } & N & Mean & Std. Deviation & \multirow{2}{*}{ P value } \\
\hline \multirow{2}{*}{ Harris Hip Score Pre-operatively } & Group A & 21 & 96.81 & 4.976 & \multirow{2}{*}{0.977} \\
\cline { 2 - 6 } & Group B & 21 & 97.00 & 5.196 & \\
\hline \multirow{2}{*}{ Harris Hip Score at final follow-up } & Group A & 19 & 77.26 & 16.32 & \multirow{2}{*}{0.033} \\
\cline { 2 - 5 } & Group B & 20 & 86.95 & 10.62 & \multirow{2}{*}{} \\
\hline
\end{tabular}

There were not any incidence of surgical site infection, iatrogenic fracture, deep infection, deep venous thrombosis (DVT), decubitus ulcer, urinary tract infection, heterotrophic calcification and non- union in any group of present study.

\section{Discussion}

Intertrochanteric hip injuries represent perhaps the most important public health problem facing the orthopaedics surgeons today in developing countries like India where health care resources are limited and treatment to be offered should be efficient and cost effective ${ }^{[16]}$. Early stabilization of unstable intertrochanteric fractures with mechanically more stable implants enables early weight bearing, recovery of ambulatory function, decreases intra and postoperative complications and return to pre-fracture social community function as well as less reliance on caretakers ${ }^{[17]}$. There are two main types of fixations for trochanteric fractures, which are extramedullary plate fixation and intramedullary nailing implants $[18,19]$. Dynamic hip screw (DHS) or sliding hip screw (SHS) has been the standard implant in treating trochanteric fractures ${ }^{[10,19-25]}$. However, when compared with the intramedullary implants, it has a biomechanical disadvantage because of a longer lever arm between the weight bearing axis and the implants [13]. Intramedullary location of the junction between the nail and lag screw makes the implant stronger at resisting the bending force (reduced distance between the hip joint and the implant, diminishes the bending moment force across the implant/fracture construct) 
and the implant itself serves as a buttress against lateral translation of the proximal fragment offering a more biological method of fixation ${ }^{[19-26]}$. Treatment of unstable intertrochanteric fractures of femur with DHS and PFN is illustrated in figure 1 and 2, respectively.

The average age of presentation in study is lower to those reported in Western literature but similar to Indian studies (mean age 56.93 yrs and 56 yrs), which is comparable to our study group ${ }^{[27-33]}$. The differences in the demography may be explained by early onset of osteoporosis and increased number of road traffic accident (RTA) in Indian scenario ${ }^{[7]}$. Contrary to western literature, which have more number of female patients, sex distribution in present study was different $(\mathrm{M} ; \mathrm{F}:: 59.5 ; 40.5 \%)^{[21-23,34]} .40 .5 \%$ of patients walked with support and rest of $59.5 \%$ walked without support before injury in our study. Domestic falls like slip and fall or missed step caused fracture of trochanteric region in $61.9 \%$ of patients while rest of $35.7 \%$ suffered from RTA. RTA was one of the major causes in male population, while females having more trivial trauma induced osteoporotic trochanteric fracture.

Mean blood loss in minimum invasiveness and less soft tissue handling of CMN implants causes reduced blood loss than extramedullary implants as reflected in mean blood loss (group A and group B, $155.71 \mathrm{ml}$ and $144.29 \mathrm{ml}$ respectively). CMN need more time for proper placement of hip screws and distal locking, so operative time seem to be more than group A, (102.38 and 111.90 minutes in group A and B respectively). Intertrochanteric fractures are known to readily unite even when anatomical reduction or stable fixation is not provided mainly because of the broad metaphyseal bare fracture ends. Therefore, the mean time for complete union of intertrochanteric fractures is lesser as compared to any other long bone fractures and not significant difference observed in both the groups.

Limb length discrepancy was observed in 7 and 3 patients in group A and group B respectively, which was due to comminution at the fracture site which leads to inherent instability. Maximum shortening observed was $2 \mathrm{~cm}$ and $1 \mathrm{~cm}$ in group A and group B respectively. Implant which allows collapse at fracture site (Group A > Group B) is responsible for limb shortening. For a dynamic device to work without excessive collapse, a majority of bone along the femur's circumference should remain intact and in contact.

Mean Sliding of implant in group A and group B were 0.63 $\mathrm{cm}$ and $0.72 \mathrm{~cm}$ with maximum $1 \mathrm{~cm}$ and $1.3 \mathrm{~cm}$ respectively, contrary to Kyle et al. and Hardy et al. where they found less sliding in CMN implants $[35,36]$. Mean Immediate post operative neck shaft angle in group A and group B were 131.95 and 130.14 degree respectively. Fracture were fixed in slight valgus position because extramedullary and CMN allows varus angulations of fracture, so at final follow-up we gain normal limb. Mean difference in immediate post operative to final follow-up neck shaft angle was 5.89 degree and 1.85 degree in group A and group B respectively. Compare to our study Pajarinen et al. Domingo et al. and Olsson et al. had recorded $>5$ degree of change in neck shaft angle in patients treated with DHS [34, 37, 38]. More fracture collapse and varus angulations has been observed in group A, that's why neck shaft angle from immediate post-operative to final follow-up varied more with DHS/DCS implant.

Mean Parker mobility score in group A and group B were 8 and 8.05 , pre-operatively while at 6 month post operatively score were 5.95 and 6.80 respectively, while values were 2 and 4 for DHS and CMN group respectively according to Chua et al ${ }^{[17]}$. In group $1,47.3 \%$ patients were community mobile, $31.5 \%$ were outdoor mobile and $21 \%$ were indoor mobile. In group 2, 55\% patients were community mobile, $30 \%$ were outdoor mobile and $15 \%$ were indoor mobile. Mean Environmental mobility score at 6 month in group 1 and group 2 were 2.26 and 2.40, which was higher than Chua et al (1 and 2 for DHS and CMN group respectively) ${ }^{[17]}$. In group $1,31.6 \%$ patients were independently mobile, $42.1 \%$ needed single arm aid, $21 \%$ needed double arm aid and 5.3\% were wheelchair bound where in Group 2, 55\% were independently mobile, $45 \%$ required single arm aid and $20 \%$ needed double arm aid at six months follow up. In CMN group $20 \%, 56 \%, 16 \%$ and $8 \%$ patients were independently mobile, single arm aid walking, double arm aid walking and wheelchair bound respectively. Chua et al. had 3\%, 42\%, $26 \%, 3 \%$ and $26 \%$ patients walking independently, with single arm aid, with double arm aid, with personal assistance and wheelchair bound respectively in DHS group [17]. Ambulatory independence score at 6 month in group 1 and group 2 were 3.94 and 4.15 respectively; values were comparable (3 and 4) according to Chua et al. ${ }^{[17]}$. Both the implant have comparable function outcome in term of mobilization status of patients. In Group 1 and group 2 there were no limp ( $31.57 \%$ vs. $50 \%)$, mild limp (36.84\% vs. $35 \%)$, and moderate limp $(31.57 \%$ vs. $15 \%)$ at last follow up. Difference of limp in both the group was not statistically significant.

Functional outcomes were evaluated in form of mean Harris hip score at 6 months and difference of both the groups was statistically significant $(\mathrm{p}=0.033)$. Ozkan et al. recorded mean Harris hip score 74.66 while values were recorded 71.0 by Lavini et al. in patients treated with cephalomedullary nail [39, 40]. Bhakat et al. recorded 78.8 and 82.8 and $\mathrm{Yu}$ et al. observed 87.2 and 88.2 scores at 6 month in DHS group and Cephalomedullary group respectively ${ }^{[7,33]}$. As CMN is an intra medullary load sharing device as compared to load bearing as extramedullary implants, allows early weight bearing and active mobilization resulting better early functional outcomes. Even though the final outcome was not statistically significant, it can be derived from our study that, the pre-injury functional levels are attained earlier with Cephalomedullary nail as compared to extramedullary implants hence giving Cephalomedullary Nail (CMN) edge over extramedullary implant. Additionally there were other benefits including lesser soft tissue insult and lesser intraoperative blood loss, while accounting the co-morbid conditions and osteoporosis prevalence in India and better functional outcomes with CMN. 


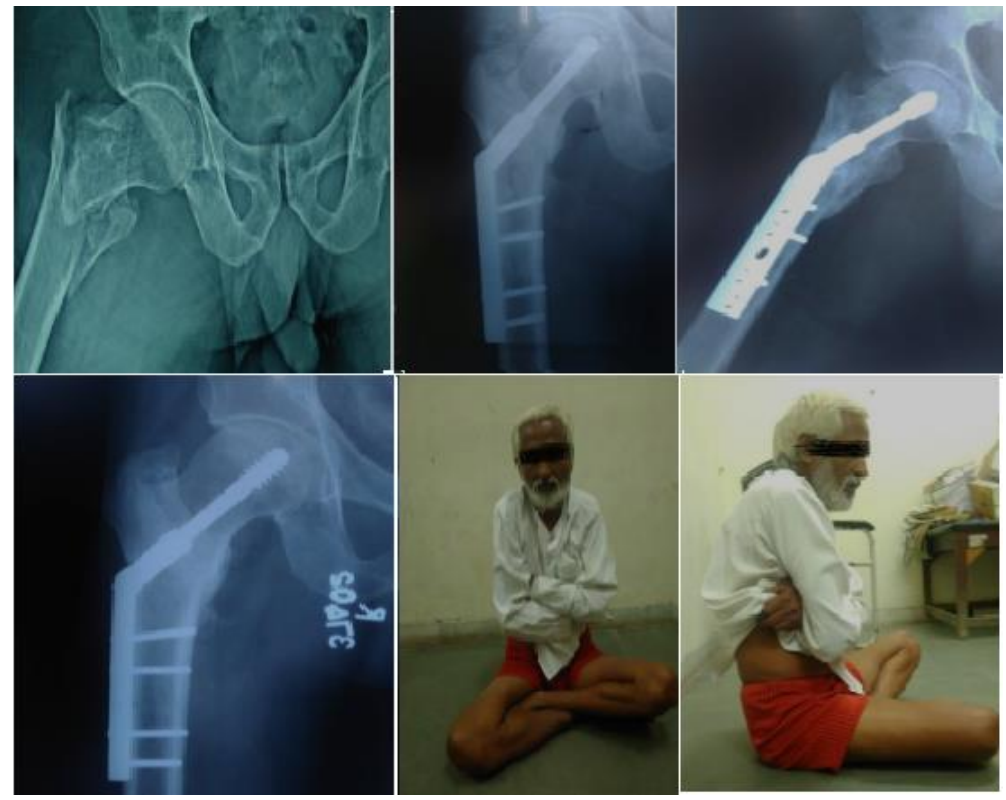

Fig 1: First row showing unstable intertrochanteric fracture of femur in 62 year old male 1) Plane radiograph (AP view), 2) Postoperative radiograph after fixation (CRIF) with DHS, 3) Plane radiograph at 3 months with callus formation. Second row showing 1) Plane radiograph at 6 months follow-up with complete union at fracture site, 2) and 3) pictures showing full functional movements of the hips and knees with cross leg posture.

One patient in group 1 had broken DHS barrel plate with varus collapse at fracture site for which patient was reoperated another patient had DHS cut-out from head due to poor placement of screw, he was lost to follow-up. Higher reoperation incidence (6 patients out of 112) was observed by $\mathrm{Yu}$ et al. in their study ${ }^{[33]}$. The other one patient in group 2 died due to cause not related to surgical procedure.
Comparison of Screw cut out as a complication of present study to other studies shown in Table 4. Kouvidis et al. observed DHS plate pulled off in one patient, while Domingo et al. had fracture of greater trochanter during nail insertion in 9 cases ${ }^{[34,41]}$. We had no such complications and morbidity in present prospective study.
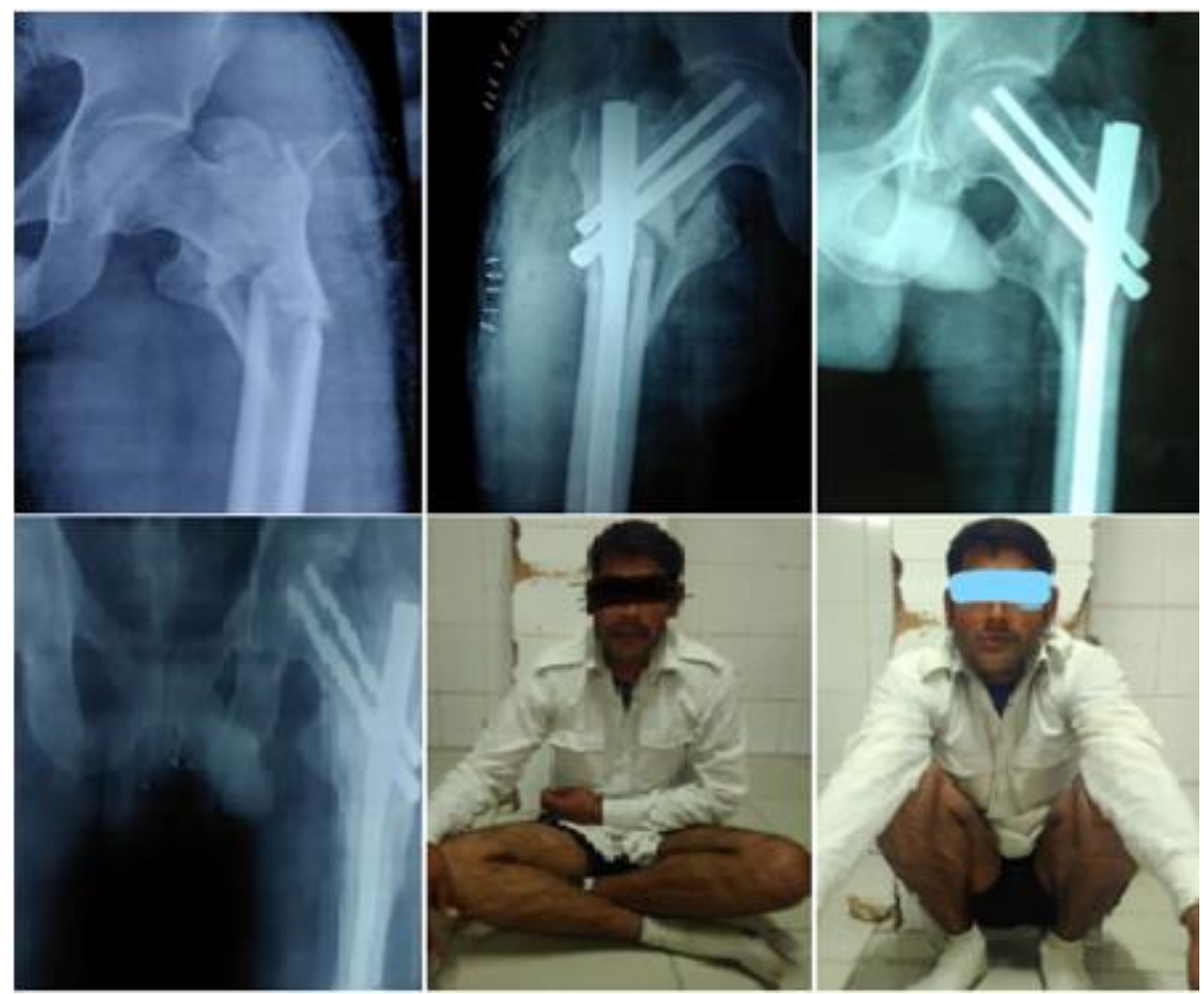

Fig 2: First row showing unstable intertrochanteric fracture of femur in 28 year old male 1) Plane radiograph (AP view), 2) Post-operative radiograph after fixation (CRIF) with PFN, 3) Plane radiograph at 3 months with callus formation. Second row showing 1) Plane radiograph at 6 months follow-up with complete union at fracture site, 2) and 3) pictures showing full functional movements of the hips and knees with cross leg and squatting posture. 
Table 4: Comparison of complications as Screw cut out in present study to other studies shown in tabulated form.

\begin{tabular}{|c|c|c|c|}
\hline \multirow{2}{*}{ Comparative Studies } & \multirow{2}{*}{ Total subjects } & \multicolumn{2}{|c|}{ Screw cut out } \\
\cline { 3 - 4 } & & Gp A & Gp B \\
\hline Chua et al. & 63 & 1 & 1 \\
\hline Kouvidis et al. & 165 & 5 & 0 \\
\hline Fang et al. & 234 & 1 & - \\
\hline Boldin et al. & 55 & - & 2 \\
\hline Domingo et al. & 295 & - & 4 \\
\hline Present study & 42 & 1 & 0 \\
\hline
\end{tabular}

\section{Limitation}

There was small sample size with short follow-up period of 6 months for comparison in both groups, which was not enough and sufficient to conclude outcomes, so we recommend a large study or a multicentre trials with long term follow-up and results.

\section{Conclusions}

Final outcomes were assessed by Harris hip score, environmental mobility score and ambulatory independence score, which revealed that treatment of intertrochanteric fracture with Cephalomedullary nail provides early postoperative mobilization, less intra operative blood loss, less reduction in neck-shaft angle resulting less limb length discrepancy and better functional outcome compared to those treated with extramedullary implants. More radiation exposure required for Cephalomedullary nail than DHS/DCS. Lateral position is also a good option for fixation of CMN, preferably where fracture table assembly is non-functional or not available. Thus both modalities of treatment can be safely used in trochanteric fracture by the surgeon at peripheral hospitals with or without assistance of fracture table. These fractures are of geriatric population and should be managed to accounting age, configuration of fracture, and severity of injury, bone quality and patient's physiological status.

Conflict of interest: No authors declare any conflict.

\section{Source of support: Nil.}

Informed consent and acknowledgement: Informed consent was taken from the patient and all the participants for the procedures and treatment. We are thankful to all the patients and participants involved in the present study.

\section{References}

1. Russell TA, Sanders R. Pertrochanteric hip fractures: Time for change. J Orthop Trauma. 2011; 25(4):189-190.

2. Kannus P, Oarkkari J, Sievänen H. Epidemiology of hip fractures. Bone. 1996; 18:57-63.

3. Gullberg B, Duppe H, Nilsson B. Incidence of hip fractures in Malmö, Sweden (1950-1991). Bone. 1993; $14: 23-9$

4. Hornby R, Evans JG, Vardon V. Operative or conservative treatment for trochanteric fractures of the femur: a randomized epidemiological trial in elderly patients. J Bone Joint Surg Br. 1989; 71(4):619-23.

5. Bong SC, Lau HK, Leong JC, Fang D, Lau MT. The treatment of unstable intertrochanteric Fractures of the hip: A prospective trial of 150 cases. Injury. 1981; 13(2):139-146.

6. Jain R, Basinski A, Kreder HJ. Nonoperative treatment of hip fractures. Int Orthop. 2003; 27:11-17.

7. Bhakat U, Bandyopadhayay R. Comparative study between proximal femoral nailing and dynamic hip screw in Intertrochanteric fractures of femur. Open journal of orthopaedics. 2013; 3:291-95.

8. Zuckerman J D. Comprehensive care of orthopaedic injuries in the elderly. Baltimore. Urban and Schwarzenberg, 1990, 23-111.

9. Korkmaz MF, Erdem MN, Disli ZE, Selcuk EB, Karakaplan M, Gogus A. et al Outcomes of trochanteric femoral fractures treated with proximal femoral nail: an analysis of 100 consecutive cases. Clin Interven Aging. 2014; 9:569-74.

10. Pajarinen J, Lindahl J, Michelsson O, Savolainen V, Hirvensalo E. Pertrochanteric femoral fracturs treated with a dynamic hip screw or a proximal femoral nail. J Bone Joint Surg (Br). 2005; 87:76-81.

11. Al-yassari G, Langstaff RJ, Jones JW, Al-Lami M. The AO/ASIF proximal femoral nail (PFN) for the treatment of unstable trochanteric femoral fracture. Injury. 2002; 33(5):395-399.

12. Banan H, Al-Sabti A, Jimulia T, Hart AJ. The treatment of unstable, extracapsular hip fractures with the AO/ASIF proximal femoral nail (PFN) — our first 60 case. Injury. 2002; 33(5):401-405.

13. Parker MJ, Handoll HH. Gamma and other cephalocondylic intramedullary nails versus extramedullary implants for extracapsular hip fractures in adults. Cochrane Database Syst Rev, 2008, 16(3). CD000093.

14. Kristensen MT, Foss NB, Ekdahl C, Kehlet H. Prefracture functional level evaluated by the New Mobility Score predicts in hospital outcome after hip fracture surgery. Acta Orthop. 2010; 81:296-302.

15. Harris WH. Traumatic arthritis of the hip after dislocation and acetabular fractures: treatment by mold arthroplasty. An end result study using a new method of result evaluation. J bone Joint Surg (Am). 1969; 51:737-55.

16. Zuckerman JD, Sakales SR, Fabian DR et al. Hip fractures in geriatric patients. Results of an interdisciplinary hospital care program. Clin Orthop. 1992; 274:213-225.

17. Chua ITH, Rajamoney GN, Kwek BKK. Cephalomedullary nail versus sliding hip screw for unstable intertrochanteric fractures in elderly patients. Journal of Orthopaedic Surgery. 2013; 21(3):308-12.

18. Utrilla L, Reig JS, Munoz FM, Tufanisco CB, Trochanteric gamma nail and compression hip screw for trochanteric fractures: a randomized, prospective, comparative study in 210 elderly patients with a new design of the gamma nail, Journal of Orthopaedic Trauma. 2005; 19(4):229-233.

19. Parker MJ, Handoll HH, Gamma and other cephalocondylic intramedullary nails versus extramedullary implants for extracapsular hip fractures, Cochrane Database of Systematic Reviews, 2002, 4. CD000093.

20. Butt MS, Krikler SJ, Nafe S, Ali MS, Comparison of 
dynamic hip screw and gamma nail: a prospective, randomized, controlled trial, Injury. 1995; 26(9):615-618.

21. Bridle SH, Patel AD, Bircher M, Calvert PT, Fixation of intertrochanteric fractures of the femur. A randomized prospective comparison of the gamma nail and the dynamic hip screw, Journal of Bone and Joint Surgery B. 1991; 73(2):330-334.

22. Goldhagen PR, O'Connor DR, Schwarze D, Schwartz E. A prospective comparative study of the compression hip screw and the gamma nail, Journal of Orthopaedic Trauma. 1994; 8(5):367-372.

23. Hoffman CW, Lynskey TG. Intertrochanteric fractures of the femur: A randomized prospective comparison of the gamma nail and the AMBI hip screw, Australian and New Zealand Journal of Surgery. 1996; 66(3):151-155.

24. Radford PJ, Needoff M, Webb JK. A prospective randomized comparison of the dynamic hip screw and the gamma locking nail, Journal of Bone and Joint Surgery B. 1993; 75(5):789-793.

25. Parker MJ, Handoll H. Gamma and other cephalocondylic intramedullary nails versus extramedullary implants for extracapsular hip fractures in adults, Cochrane Database of Systematic Reviews, 2010, 16(3). CD000093.

26. Thakur A. The elements of fracture fixation. 1st Ed. New York: Churchill Livingston, 1997.

27. Kamboj P, Siwach R, Kundu ZS, Sangwan S, Walecha P, Singh R. et al. Results of Modified Proximal Femoral Nail in Peritrochanteric Fractures in adults. The Internet Journal of Orthopaedics Surgery, 2007, 6(2).

28. Endigeri P, Pattanashetty OB, Banapatti DB, Pillai A, Ullas T. Outcome of intertrochanteric fractures treated with proximal femoral nail: A prospective study. JOTR. 2015; 8(1):25-29.

29. Tyllianakis M, Panagopoulos A, Papadopoulos A, Papasimos S, Mousafiris K. Treatment of extracapsular hip fractures with the proximal femoral nail (PFN): long term results in 45 patients. Acta Orthop Belg. 2004; 70:444-54.

30. Gupta RK, Sangwan K, Kamboj P, Punia SS, Walecha P. Unstable trochanteric fractures: the role of lateral wall reconstruction. Int Orthop. 2010; 34(1):125-29.

31. Matre K, Havelin LI, Gjertsen JE, Espehaug B, Fevang J M. Sliding hip screw versus IM nail in reverse oblique trochanteric and subtrochanteric fractures. A study of 2716 patients in Norwegian hip fracture register. Injury. 2013; 44(6):735-42.

32. Niu E, Yang A, Harris AHS, Bishop J. Which Fixation Device is Preferred for Surgical Treatment of Intertrochanteric Hip Fractures in the United States? A Survey of Orthopaedic Surgeons. Clin Orthop Relat Res. 2015; 473:3647-55.

33. Yu W, Zhang X, Zhu X, Yu Z, Xu Y, Zha G et al. Proximal femoral nails anti-rotation versus dynamic hip screws for treatment of stable intertrochanteric femur fractures: an outcome analyses with a minimum 4 years of follow-up. BMC Musculoskeletal Disorders, 2016, 17(1).

34. Domingo L, Cecilia D, Herrera A, Resines C. Trochanteric fractures treated with a proximal femoral nail. Int Orthop. 2001; 25:298-301.

35. Kyle RF, Wright TM, Burstein AH. Biomechanical analysis of the sliding characteristics of compression hip screws. J Bone Joint Surg Am. 1980; 62:1308-1314.

36. Hardy D, Descamps P, Krallis P. Use of an intramedullary hip screw compared with a compression hip screw with a plate for intertrochanteric femoral fractures. A prospective randomized study of one hundred patients. J Bone Joint Surg Am. 1998; 80:618630.

37. Pajarinen J, Lindahl J, Savolainen V, Michelsson O, Hirvensalo E. Femoral shaft medialisation and neck-shaft angle in unstable pertrochanteric femoral fractures International Orthopaedics (SICOT). 2004; 28:347-353.

38. Olsson O, Ceder L, Hauggaard A. Femoral shortening in intertrochanteric fractures. A comparison between the Medoff sliding plate and the compression hip screw. J Bone Joint Surg Br. 2000; 83(4):572.

39. Ozkan K, Eceviz E, Unay K, Tasyikan L, Akman B, Eren A. et al. Treatment of reverse oblique trochanteric femoral fractures with proximal femoral nail. International Orthopaedics (SICOT). 2011; 35:595-598.

40. Lavini F, Renzi-Brivio L, Aulisa R, Cherubino F, Di Seglio PL, Galante N, et al. the treatment of stable and unstable proximal femoral fractures with a new trochanteric nail: results of a multicentre study with the Veronail. Strategies Trauma Limb Reconstr. 2008; 3(1):15-22.

41. Kouvidis G, Sakellariou VI, Mavrogenis AF, Stavrakakis J, Kampas D, Galanakis J, et al. Dual lag screw cephalomedullary nail versus the classic sliding hip screw for the stabilization of intertrochanteric fractures. A prospective randomized study. Strategies Trauma Limb Reconstr. 2012; 7(3):155-162. 